\title{
EVALUASI PENGOLAHAN DAN MUTU BAHAN OLAH KARET RAKYAT (BOKAR) DI TINGKAT PETANI KARET DI SUMATERA SELATAN
}

\author{
Evaluation of Processing and Quality of Raw Rubber Material \\ at Smallholder's Level in South Sumatra \\ Lina Fatayati SYARIFA, Dwi Shinta AGUSTINA, dan Cicilia NANCY \\ Balai Penelitian Sembawa, Pusat Penelitian Karet \\ Jalan Raya Palembang - P. Balai KM 29, PO BOX 1127 Palembang 30001 \\ Email : lina_fsy@yahoo.com
}

Diterima tanggal 16 Oktober 2012 / Disetujui tanggal 26 April 2013

\begin{abstract}
The study was conducted to evaluate the enforcement of government regulations to processing and quality of raw rubber material at smallholder level. This study was conducted by survey method. Selection of location was made purposively by selecting the central areas of rubber. Data were collected by Focus Group Discussion (FGD) method involving village officers. The farmers were then interviewed and followed by visual observation of rubber quality at smallholder level. The survey results showed that the enforcement of the Regulation of Agriculture Minister and the Regulation of Trade Minister had not been done widely at smallholder level, because marketing agencies still accepted the low quality raw rubber material produced by farmers. The problems of rubber processing and marketing that caused the low quality of raw rubber material and the low of farmers' income were still found in Musi Rawas and Lubuk Linggau Regencies. Serious attention was needed to solve the problems.
\end{abstract}

Keywords: Raw rubber material, quality, processing, smallholder

\footnotetext{
Abstrak

Penelitian dilakukan untuk meng-evaluasi penerapan peraturan-peraturan pemerintah terhadap sistem pengolahan dan mutu bokar di tingkat petani. Penelitian dilakukan dengan metode survei dengan memilih sampel secara purposive, yaitu daerah-daerah yang merupakan sentra karet. Pengambilan data dilakukan melalui metode Focus Group Discussion (FGD) yang melibatkan perangkat-perangkat desa dan diikuti wawancara dengan petani dan pengamatan visual terhadap mutu bokar yang dihasilkan petani. Hasil survei menunjukkan bahwa penerapan Permentan dan Permendag belum dilaksanakan sepenuhnya di tingkat petani. Hal ini dikarenakan peraturan dari lembaga pemasaran yang belum tegas untuk menolak bokar mutu rendah yang dihasilkan petani. Permasalahan pengolahan dan pemasaran karet yang menyebabkan rendahnya
}

mutu bokar dan pendapatan petani masih banyak terjadi di Kabupaten Musi Rawas dan Kota Lubuk Linggau yang masih memerlukan perhatian serius.

Kata kunci: Bokar, mutu, pengolahan, petani karet

\section{PENDAHULUAN}

Indonesia merupakan negara produsen dan pengekspor karet alam utama dunia setelah Thailand. Karet alam merupakan komoditas strategis karena kontribusinya yang besar terhadap penerimaan devisa negara (US\$ 7,3 Milyar), penyerapan tenaga kerja dan menjadi sumber pendapatan bagi 2 juta kepala keluarga tani di pedesaan (Gapkindo, 2010; Direktorat Jenderal Perkebunan, 2011). Perkebunan karet di Indonesia didominasi oleh perkebunan karet rakyat. Pada tahun 2011, perkebunan karet rakyat telah meliputi areal seluas 2,9 juta hektar atau sekitar 85\% dari total areal karet nasional, dengan produksi sekitar $80 \%$ dari total produksi karet alam nasional (Tabel 1).

Menyadari pentingnya sektor perkebunan karet rakyat bagi kepentingan perekonomian nasional, pemerintah sejak lama telah berupaya memperbaiki dan mengembangkan sektor ini. Karena maju mundurnya kinerja industri karet alam di dalam negeri akan memberikan dampak cukup luas bagi kesejahteraan masyarakat. Saat ini, permasalahan utama di perkebunan karet rakyat yang belum terpecahkan adalah bahan baku yang dihasilkan umumnya bermutu rendah akibat penanganan bokar yang kurang baik dan sistem pemasaran bokar yang belum efisien (Balai Penelitian Sembawa, 2009). 
Tabel 1. Luas areal perkebunan rakyat Indonesia berdasarkan provinsi penghasil karet, 2011 Table 1. Rubber area of smallholders in Indonesia by rubber producing provinces, 2011

\begin{tabular}{|c|c|c|c|c|c|c|}
\hline \multirow[b]{2}{*}{ No } & \multirow[b]{2}{*}{$\begin{array}{l}\text { Provinsi } \\
\text { Province }\end{array}$} & \multicolumn{5}{|c|}{$\begin{array}{c}\text { Perkebunarrakyat } \\
\text { Smallholders }\end{array}$} \\
\hline & & $\begin{array}{l}\text { Luas } \\
\text { Area } \\
\text { (ha) }\end{array}$ & $\begin{array}{l}\text { Produksi } \\
\text { (Ton) } \\
\text { Production } \\
\text { (Tonnes) }\end{array}$ & $\begin{array}{l}\text { Produktivitas } \\
\text { Productivity } \\
\text { (kg/ha) }\end{array}$ & $\begin{array}{l}\text { Jumlah } \\
\text { petani } \\
\text { Number of } \\
\text { Farmers } \\
\text { (KK) }\end{array}$ & $\begin{array}{c}\text { Rerata } \\
\text { kepemilikan } \\
\text { Average } \\
\text { ownership } \\
\text { (ha) }\end{array}$ \\
\hline 1. & Aceh & 76.113 & 67.844 & 1.001 & 59.699 & 1,27 \\
\hline 2. & Sumatera Utara & 297.001 & 268.078 & 986 & 169.873 & 1,75 \\
\hline 3. & Sumatera Barat & 126.482 & 107.127 & 1.217 & 103.746 & 1,22 \\
\hline 4. & Riau & 357.147 & 377.534 & 1.181 & 191.813 & 1,86 \\
\hline 5. & Jambi & 436.973 & 360.389 & 984 & 162.936 & 2,68 \\
\hline 6. & Sumatera Selatan & 620.439 & 583.881 & 1.155 & 756.933 & 0,82 \\
\hline 7. & Kep. Bangka Belitung & 29.486 & 23.587 & 1.152 & 21.453 & 1,37 \\
\hline 8. & Bengkulu & 60.225 & 50.372 & 1.053 & 44.958 & 1,34 \\
\hline 9. & Lampung & 50.979 & 44.378 & 1.157 & 51.025 & 1,00 \\
\hline 10. & Kalimantan Barat & 381.205 & 260.559 & 826 & 199.773 & 1,91 \\
\hline 11. & Kalimantan Tengah & 257.521 & 192.627 & 1.003 & 139.608 & 1,84 \\
\hline 12. & Kalimantan Selatan & 113.203 & 85.271 & 956 & 95.655 & 1,18 \\
\hline 13. & Kalimantan Timur & 49.289 & 19.244 & 825 & 27.893 & 1,77 \\
\hline 14. & Lainnya & 75.781 & 45.132 & 1.002 & 74.948 & 1,01 \\
\hline \multicolumn{2}{|c|}{ Total Indonesia } & 2.931 .844 & 2.486 .023 & 1.036 & 2.100 .313 & 1,40 \\
\hline
\end{tabular}

Sumber (Source): Direktorat Jenderal Perkebunan (Directorate General of Estate), 2011

Inefisiensi sistem pemasaran mengakibatkan rendahnya harga yang diterima petani sehingga mereka tidak tertarik untuk meningkatkan produksi maupun mutu bokar yang dihasilkannya. Para konsumen karet Indonesia seringkali mengeluh, karena mutu produk yang dihasilkan kurang seragam dan kurang konsisten. Terkait dengan hal tersebut adalah munculnya keluhan dari beberapa pihak pengimpor karet alam (terutama pabrik ban) terhadap mutu crumb rubber asal Indonesia, karena disinyalir mengandung kotoran dan kadar abu yang tinggi yang sangat berpengaruh terhadap mutu produk karet hilirnya. Rendahnya mutu bokar akan menurunkan daya saing karet alam indonesia di pasar Internasional.

Melihat berbagai permasalahan tersebut telah ditempuh upaya untuk memperbaiki daya saing karet nasional. Salah satu upaya yang telah dilakukan oleh pemerintah adalah mengeluarkan peraturan yaitu Peraturan Menteri Pertanian No. 38/Permentan/OT.140/8/2008 tentang Pedoman Pengolahan dan Pemasaran Bahan Olah Karet (bokar) dan Peraturan Menteri
Perdagangan No. 53/M-DAG/PER/10/2009 tentang Pengawasan Mutu Bahan Olah Komoditi Ekspor Standard Indonesian Rubber yang diperdagangkan yang berlandaskan SNI No. 06-2047-2002 tentang BOKAR dan UU No.18 Tahun 2004 tentang Perkebunan. Agar kebijakan tersebut dapat berjalan efektif maka dicanangkan suatu gerakan yang bersifat nasional dalam bentuk Gerakan Nasional Bokar Bersih (GNBB). Salah satu tujuan GNBB adalah menghasilkan bokar bersih dan bermutu sesuai dengan persyaratan teknis dan yang berlaku, dan memperbaiki serta meningkatkan nilai pendapatan masing-masing pihak yang terkait secara proporsional dimulai dari tingkat petani, pedagang, industri pengolahan bokar hingga eksportir. Upaya tersebut perlu ditangani secara terpadu oleh seluruh pihak terkait baik pemerintah, pengusaha karet, pedagang dan petani. Namun bagaimana dampak dari penerapan peraturan tersebut di lapangan, perlu dilakukan pengamatan lebih lanjut. Penelitian ini dilakukan untuk mengevaluasi penerapan peraturan tersebut terhadap sistem pengolahan dan mutu bokar di tingkat petani karet. 


\section{BAHAN DAN METODE}

Penelitian dilakukan pada bulan Juni -Desember 2011 di Sumatera Selatan dengan menggunakan metode survei. Kegiatan dilakukan dengan memilih sampel secara purposif, yaitu pada tahap pertama dipilih kabupaten yang dinilai merupakan daerah sentra produksi karet, dilanjutkan dengan pemilihan kecamatan yang juga merupakan sentra produksi karet. Pada kecamatan tersebut contoh desa diambil secara purposif dengan kriteria merupakan desa penghasil karet. Di tingkat desa pengambilan data dilakukan melalui metode Focus Group Discussion (FGD) yang melibatkan perangkat-perangkat desa (Sekdes, BPD atau Kelompok tani), dilanjutkan wawancara dengan petani karet dan pengamatan secara visual terhadap cara pengolahan dan mutu bokar yang dihasilkan petani. Peubah yang dikaji dapat dikelompokkan menjadi:

1. Volume dan umur simpan bokar

2. Mutu bokar, termasuk tingkat kebersihan, berat bokar, jenis bokar, bahan pembeku, penyimpanan dan pencetakan bokar. Bokar yang bersih adalah bokar yang dinilai hanya mengandung kotoran tatal sebesar maksimum 5\%, apabila kotoran tatal yang dikandung melebihi $5 \%$ maka dikategorikan bokar kotor.

Survei dilakukan di 9 kabupaten/ kota, 45 kecamatan, dan 85 desa seperti tertera pada Tabel 2 dan Lampiran 1 .

\section{HASIL DAN PEMBAHASAN}

Kajian sosial ekonomi ini dilakukan dalam rangka mengevaluasi sejauh mana dampak dari adanya Peraturan Menteri Pertanian dan Menteri Perdagangan mengenai bokar bersih terhadap sistem pengolahan dan mutu bahan olah karet rakyat (bokar) di wilayah-wilayah sentra karet di Provinsi Sumatera Selatan. Dari hasil survei diperoleh informasi bahwa sosialisasi mengenai Peraturan Menteri Pertanian dan Menteri Perdagangan mengenai bokar bersih masih belum merata dilaksanakan di tingkat petani. Secara umum, sosialisasi hanya sampai di tingkat pedagang perantara, yang dilakukan pada saat menjual bokar di pabrik karet atau poolpool karet. Selanjutnya, sebagian besar pedagang menyampaikan informasi ini ke para petani. Namun, sebagian petani diantaranya masih ada yang belum mengetahui informasi tersebut. Sebaliknya, meskipun sudah mengetahui adanya peraturan tersebut, para petani belum banyak yang melaksanakannya dikarenakan masih banyaknya bokar kualitas rendah yang masih diterima oleh pedagang. Berikut ini merupakan hasil survei dan pengamatan yang dilakukan terhadap cara pengolahan mutu bokar di tingkat petani.

\section{Volume dan Umur Simpan Bokar}

Rata-rata volume bokar yang dihasilkan petani di setiap desa sampel

Tabel 2.Wilayah sampel yang terpilih dalam penelitian Table 2. Selected sampling area in the study

\begin{tabular}{clcc}
\hline No & \multicolumn{1}{c}{$\begin{array}{c}\text { Kabupaten } \\
\text { Regency }\end{array}$} & $\begin{array}{c}\text { Jumlah kecamatan } \\
\text { Number of sub districts }\end{array}$ & $\begin{array}{c}\text { Jumlah desa } \\
\text { Number of villages }\end{array}$ \\
\hline 1 & Musi Banyuasin & 6 & 11 \\
2 & Musi Rawas & 8 & 12 \\
3 & Lubuk Linggau & 1 & 2 \\
4 & Muara Enim & 9 & 15 \\
5 & Banyuasin & 4 & 14 \\
6 & OKI & 1 & 6 \\
7 & Ogan Ilir & 6 & 3 \\
8 & OKU Induk & 6 & 11 \\
9 & OKU Timur & 45 & 11 \\
\hline Total & 9 & & 85 \\
\hline
\end{tabular}


sebesar 133 ton per bulan. Sebagian besar bokar petani dijual secara mingguan (55\%) ke pedagang/tengkulak baik secara individu maupun berkelompok. Petani yang menjual bokar secara bulanan atau 2 mingguan sebagian besar merupakan peserta kelompok yang menjual bokar melalui tender di kelompok pemasaran maupun KUD (Tabel 3).

Tabel 3. Volume dan umur simpan bokar di tingkat petani di Sumatera Selatan, 2011

Table 3. Volume and shelf life of raw rubber material in Smallholder level in South Sumatera, 2011

\begin{tabular}{|c|c|c|c|c|c|}
\hline \multirow{2}{*}{$\begin{array}{c}\text { Kabupaten } \\
\text { Regency }\end{array}$} & \multirow{2}{*}{$\begin{array}{c}\text { Volume Bokar di desa } \\
\text { (ton/bulan) } \\
\text { Raw rubber material } \\
\text { volume at village } \\
\text { (Tonnes/month) }\end{array}$} & \multicolumn{4}{|c|}{$\begin{array}{c}\text { Umur Simpan Bokar } \\
\text { Raw rubber material shelf life } \\
\%\end{array}$} \\
\hline & & $\begin{array}{l}1 \text { Bulan } \\
1 \text { Month }\end{array}$ & $\begin{array}{l}2 \text { Minggu } \\
2 \text { Weeks }\end{array}$ & $\begin{array}{l}1 \text { Minggu } \\
1 \text { Week }\end{array}$ & $\begin{array}{c}\text { Harian } \\
\text { Days }\end{array}$ \\
\hline Muara Enim & 190 & 23 & 23 & 45 & 9 \\
\hline Banyuasin & 145 & 19 & 4 & 46 & 31 \\
\hline Musi Banyuasin & 122 & 18 & 10 & 72 & 0 \\
\hline OKU Timur & 74 & 33 & 33 & 27 & 8 \\
\hline OKI & 223 & 11 & 22 & 65 & 2 \\
\hline Ogan Ilir & 140 & 0 & 0 & 100 & 0 \\
\hline OKU Induk & 74 & 9 & 39 & 52 & 0 \\
\hline Musi Rawas & 172 & 25 & 5 & 45 & 25 \\
\hline Lubuk Linggau & 60 & 18 & 0 & 38 & 45 \\
\hline Sumatera Selatan & 133 & 17 & 15 & 55 & 13 \\
\hline
\end{tabular}

Sumber (Source): Data primer (Prime data)

\section{Mutu Bokar}

Sebagian besar petani menghasilkan bokar dalam bentuk slab lump (99\%). Sebanyak $64 \%$ petani telah menghasilkan slab bersih dan sisanya sebanyak $36 \%$ petani masih menghasilkan slab yang dicampur dengan tatal (kulit kayu sadapan). Rata-rata ketebalan slab yang dihasilkan petani lebih dari $10 \mathrm{~cm}$ dengan berat slab berkisar $28-80$ kg per keping (Tabel 4). Para petani lebih menyukai slab tebal karena alasan menghindari pencurian slab, sedangkan bagi pedagang/tengkulak, dengan membeli slab tebal risiko penyusutan kadar air lebih besar, sehingga pedagang cenderung menekan harga bokar karena alasan tingginya kadar air.

Dilihat dari cara pengolahan bokar, sebagian besar petani banyak menggunakan bahan pembeku yang tidak direkomendasikan yaitu asam sulfat (66\%) yang lebih dikenal masyarakat dengan sebutan cuka para. Cuka para merupakan bahan pembeku yang paling mudah didapat di pasaran.
Penggunaan bahan pembeku tawas dan pupuk TSP juga masih banyak dilakukan oleh petani. Sebagian besar petani di wilayah Kabupaten Muara Enim dan Kabupaten OKI menggunakan pembeku cuka para yang dicampur dengan tawas (Tabel 5). Selain itu terdapat juga bahan pembeku lain yang juga tidak direkomendasikan antara lain, gadung, dan air cucian tempe. Penggunaan bahan pembeku yang tidak direkomendasikan seperti tawas, pupuk TSP, dan gadung pada bokar, dapat menyebabkan mutu karet menjadi rendah dikarenakan nilai plastisitas karet, baik plastisitas awal (Po) maupun plastisitas retensi indeks (PRI) akan turun di bawah standar SIR 20 (Purbaya, et al., 2011).

Sebaliknya, bahan pembeku yang direkomendasikan seperti asam semut (formic acid) dan Deorub masih jarang digunakan petani. Petani hanya menggunakan Deorub atau asam semut apabila mendapat bantuan pembeku dari pemda setempat. Hal ini dikarenakan bahan pembeku Deorub dan asam semut sulit diperoleh petani di pasaran. 
Tabel 4. Tingkat kebersihan, berat dan ketebalan slab, serta jenis bokar di Sumatera Selatan, 2011

Table 4. Cleanliness level, weight, and thickness of slab, as well as types of raw rubber materials in South Sumatra, 2011

\begin{tabular}{|c|c|c|c|c|c|c|c|c|c|}
\hline \multirow[t]{2}{*}{$\begin{array}{c}\text { Kabupaten } \\
\text { Regency }\end{array}$} & \multicolumn{2}{|c|}{$\begin{array}{l}\text { Kebersihan } \\
\text { Cleanliness } \\
(\%)\end{array}$} & \multicolumn{2}{|c|}{$\begin{array}{l}\text { Berat slab/keping } \\
\text { Slab weightunit } \\
(\mathrm{kg})\end{array}$} & \multicolumn{2}{|c|}{$\begin{array}{c}\text { Ketebalan slab } \\
\text { Slab thickness } \\
(\%) \\
\end{array}$} & \multicolumn{3}{|c|}{$\begin{array}{c}\text { Jenis bokar } \\
\text { Type of raw rubber materials } \\
(\%)\end{array}$} \\
\hline & $\begin{array}{l}\text { Bersih } \\
\text { Clean }\end{array}$ & $\begin{array}{c}\text { Kotor } \\
\text { Dirt }\end{array}$ & Min. & Max. & $\begin{array}{l}<10 \\
\mathrm{~cm}\end{array}$ & $\begin{array}{l}>10 \\
\mathrm{~cm}\end{array}$ & Slab & Lump & $\begin{array}{l}\text { Slab } \\
\text { Lump }\end{array}$ \\
\hline Muara Enim & 89 & 11 & 28 & 63 & 2 & 98 & 0 & 0 & 100 \\
\hline Banyuasin & NA & NA & 31 & 89 & 0 & 100 & 0 & 0 & 100 \\
\hline $\begin{array}{l}\text { Musi } \\
\text { Banyuasin }\end{array}$ & NA & NA & 46 & 82 & 2 & 98 & 0 & 0 & 100 \\
\hline OKU Timur & 92 & 8 & 35 & 90 & 0 & 100 & 0 & 0 & 100 \\
\hline OKI & 100 & 0 & 29 & 85 & 0 & 100 & 0 & 0 & 100 \\
\hline Ogan Ilir & 100 & 0 & 20 & 60 & 0 & 100 & 0 & 0 & 100 \\
\hline OKU Induk & 64 & 36 & 26 & 91 & 0 & 100 & 0 & 0 & 100 \\
\hline Musi Rawas & 4 & 96 & 25 & 85 & 0 & 100 & 12 & 0 & 88 \\
\hline $\begin{array}{l}\text { Lubuk } \\
\text { Linggau }\end{array}$ & 0 & 100 & 13 & 80 & 0 & 100 & 0 & 0 & 100 \\
\hline $\begin{array}{l}\text { Sumatera } \\
\text { Selatan }\end{array}$ & 64 & 36 & 28 & 80 & 0,4 & 99,6 & 1 & 0 & 99 \\
\hline
\end{tabular}

- NA : data tidak tersedia (no data available)

- Sumber (Source) : Data primer (Prime data)

Tabel 5. Penggunaan bahan pembeku karet di tingkat petani di Sumatera Selatan, 2011

Table 5. Use of rubber coagulant at smallholders level in South Sumatra, 2011

\begin{tabular}{|c|c|c|c|c|c|c|c|}
\hline \multirow[b]{2}{*}{$\begin{array}{c}\text { Kabupaten } \\
\text { Regency }\end{array}$} & \multicolumn{7}{|c|}{$\begin{array}{c}\text { Bahan pembeku } \\
\text { Coagulant } \\
\% \\
\end{array}$} \\
\hline & $\begin{array}{c}\text { Deorub } \\
\mathrm{K}\end{array}$ & $\begin{array}{l}\text { Asam } \\
\text { Semut } \\
\text { Formic } \\
\text { acid }\end{array}$ & $\begin{array}{l}\text { Cuka } \\
\text { para } \\
\text { Sulfuric } \\
\text { acid }\end{array}$ & TSP & $\begin{array}{l}\text { Cuka para }+ \\
\text { tawas } \\
\text { Sulfuric acid }+ \\
\text { alum }\end{array}$ & $\begin{array}{l}\text { Tawas } \\
\text { Alum }\end{array}$ & $\begin{array}{l}\text { Lainnya } \\
\text { Others }\end{array}$ \\
\hline Muara Enim & 0 & 11 & 46 & 0 & 39 & 2 & 2 \\
\hline $\begin{array}{l}\text { Banyuasin } \\
\text { Musi }\end{array}$ & 1 & 0 & 75 & 12 & 0 & 12 & 0 \\
\hline Banyuasin & 6 & 3 & 74 & 13 & 0 & 3 & 0 \\
\hline OKU Timur & 0 & 0 & 55 & 17 & 0 & 23 & 5 \\
\hline OKI & 0 & 0 & 67 & 4 & 25 & 4 & 0 \\
\hline Ogan Ilir & 0 & 42 & 55 & 0 & 0 & 3 & 0 \\
\hline OKU Induk & 0 & 2 & 28 & 26 & 0 & 44 & 0 \\
\hline $\begin{array}{l}\text { Musi Rawas } \\
\text { Lubuk }\end{array}$ & 0 & 0 & 94 & 0 & 0 & 0 & 6 \\
\hline Linggau & 0 & 0 & 100 & 0 & 0 & 0 & 0 \\
\hline $\begin{array}{l}\text { Sumatera } \\
\text { Selatan }\end{array}$ & 1 & 7 & 66 & 8 & 7 & 10 & 1 \\
\hline
\end{tabular}

Sumber (Source) : Data primer (Prime data) 
Data pada Tabel 6 menunjukkan bahwa perendaman bokar masih banyak dilakukan oleh petani sebagai alternatif penyimpanan bokar. Perendaman bokar banyak dilakukan oleh para petani di wilayah sampel Kota Lubuk Linggau (100\%), Kabupaten Musi Rawas (93\%) dan Kabupaten OKI (62\%). Bahkan di wilayah tersebut, pencetakan dan pembekuan bokar masih ada yang dilakukan di lubang tanah. Di samping itu, sebagian besar bokar yang dihasilkan dari wilayah Kabupaten Musi Rawas dan di Kota Lubuk Linggau banyak mengandung kotoran. Jenis bahan pembeku yang digunakan petani sebagian besar cuka para, dan sebagian kecil masih mengguna-kan gadung.

Kondisi sebaliknya terjadi di wilayah Kabupaten Muara Enim dan Banyuasin. Pengolahan dan pemasaran karet di sana cukup baik, terlihat dari cara penyimpanan bokar yang sebagian besar tidak direndam dan relatif bersih. Namun, di tingkat petani masih diperlukan perbaikan terhadap penggunaan koagulan (pembeku) yang dianjurkan. Kelompok-kelompok pemasaran bokar sudah banyak terbentuk dan berkembang di wilayah tersebut. Dampak dari berkembangnya kelompok-kelompok pemasaran berpengaruh terhadap mutu bokar yang dihasilkan petani anggota. Mutu bokar yang baik terjadi karena adanya aturan kelompok yang mensyaratkan anggotanya untuk mengolah bokar sesuai standar yang diminta oleh pabrik dan adanya penghargaan terhadap mutu bokar yang dihasilkan melalui tingginya harga yang diterima oleh petani.

Kondisi penyimpanan bokar di tingkat petani di Sumatera Selatan dapat dilihat pada Gambar 1 dan 2, sementara itu kegiatan pemasaran bersama bokar disajikan pada Gambar 3.

Tabel 6. Penyimpanan dan pencetakan bokar di tingkat petani di Sumatera Selatan, 2011

Table 6. Storage and molding of raw rubber material at smallholders level in South Sumatra, 2011

\begin{tabular}{|c|c|c|c|c|c|c|}
\hline \multirow[b]{2}{*}{$\begin{array}{l}\text { Kabupaten } \\
\text { Regency }\end{array}$} & \multicolumn{2}{|c|}{$\begin{array}{l}\text { Penyimpanan Bokar } \\
\text { Raw rubber storage } \\
(\%)\end{array}$} & \multicolumn{4}{|c|}{$\begin{array}{c}\text { Tempat Pencetakan Slab } \\
\text { Slab mold } \\
(\%)\end{array}$} \\
\hline & $\begin{array}{l}\text { Direndam } \\
\text { Soaked }\end{array}$ & $\begin{array}{l}\text { Tidak } \\
\text { direndam } \\
\text { unsoaked }\end{array}$ & $\begin{array}{c}\text { Kotak } \\
\text { kayu } \\
\text { Wooden } \\
\text { box } \\
\end{array}$ & $\begin{array}{l}\text { Lubang } \\
\text { tanah } \\
\text { Ground } \\
\text { hole }\end{array}$ & $\begin{array}{l}\text { Kotak plastik } \\
\text { Plastics box }\end{array}$ & $\begin{array}{l}\text { Lainnya } \\
\text { Others }\end{array}$ \\
\hline Muara Enim & 0 & 100 & 59 & 8 & 33 & 0 \\
\hline Banyuasin & 31 & 69 & 53 & 1 & 46 & 0 \\
\hline Musi Banyuasin & 42 & 58 & 72 & 16 & 12 & 0 \\
\hline OKU Timur & 14 & 86 & 7 & 17 & 76 & 0 \\
\hline OKI & 62 & 38 & 74 & 6 & 0 & 20 \\
\hline Ogan Ilir & & & 67 & 0 & 3 & 30 \\
\hline OKU Induk & 43 & 57 & 39 & 14 & 47 & 0 \\
\hline Musi Rawas & 93 & 7 & 90 & 8 & 2 & 0 \\
\hline $\begin{array}{l}\text { Lubuk Linggau } \\
\text { Sumatera }\end{array}$ & 100 & 0 & 82 & 18 & 0 & 0 \\
\hline Selatan & 48 & 52 & 60 & 10 & 24 & 6 \\
\hline
\end{tabular}

Sumber (Source) : Data primer (Prime data) 

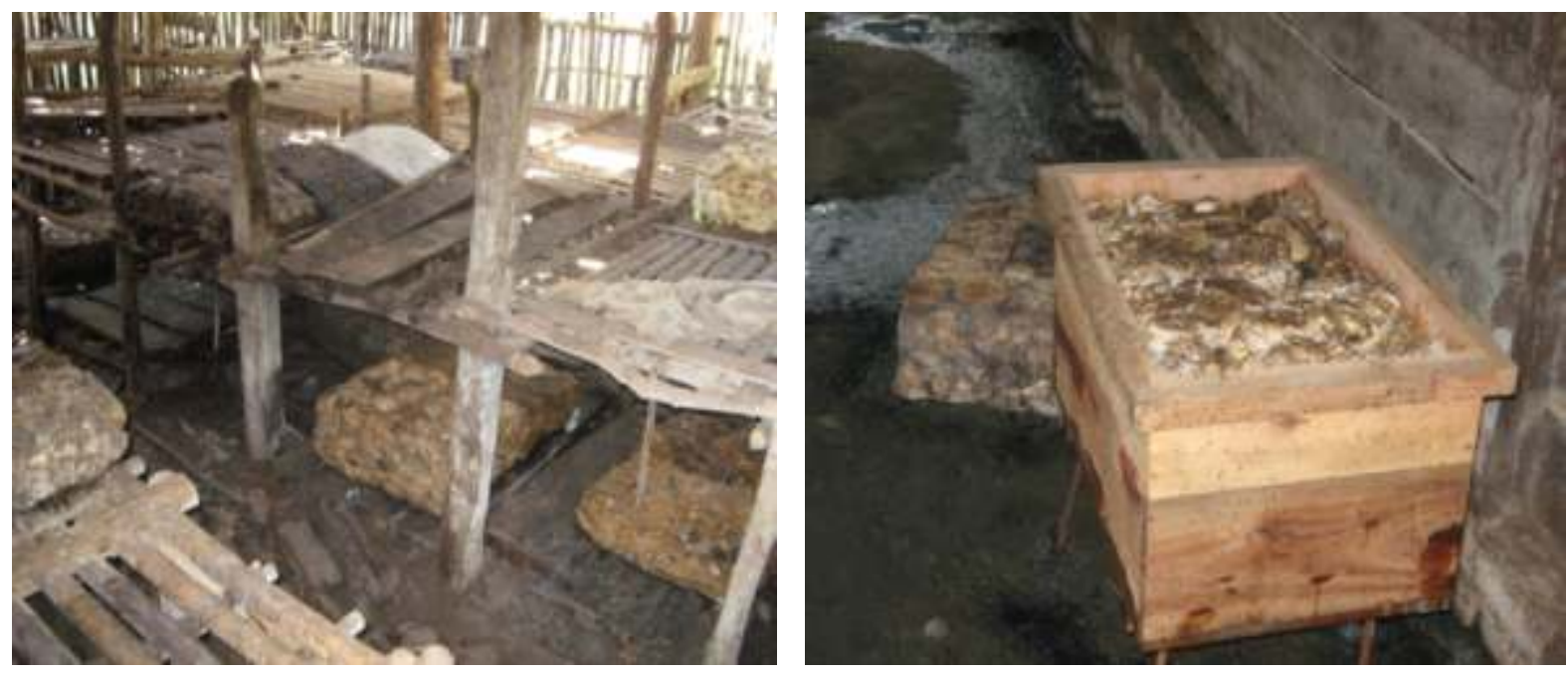

Gambar 1. Penyimpanan bokar yang baik di Kabupaten Muara Enim (kiri), dan di Banyuasin (kanan) Figure 1. Good storage of raw rubber material in Muara Enim (left) and Banyuasin Regencies (right)
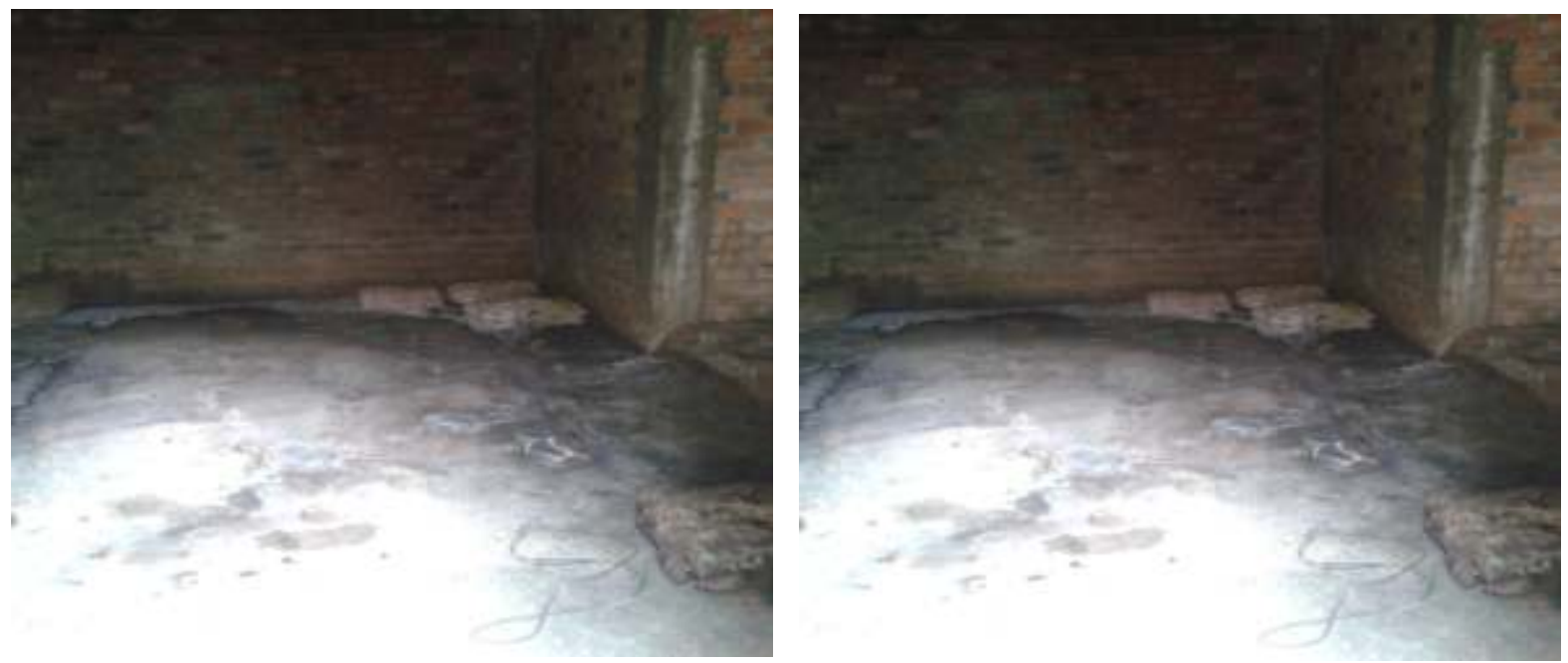

Gambar 2. Penyimpanan bokar yang tidak memenuhi standar di Kabupaten Musi Rawas dan Lubuk Linggau

Figure 2. Nonstandard storage of raw rubber material in Musi Rawas and Lubuk Linggau Regencies 

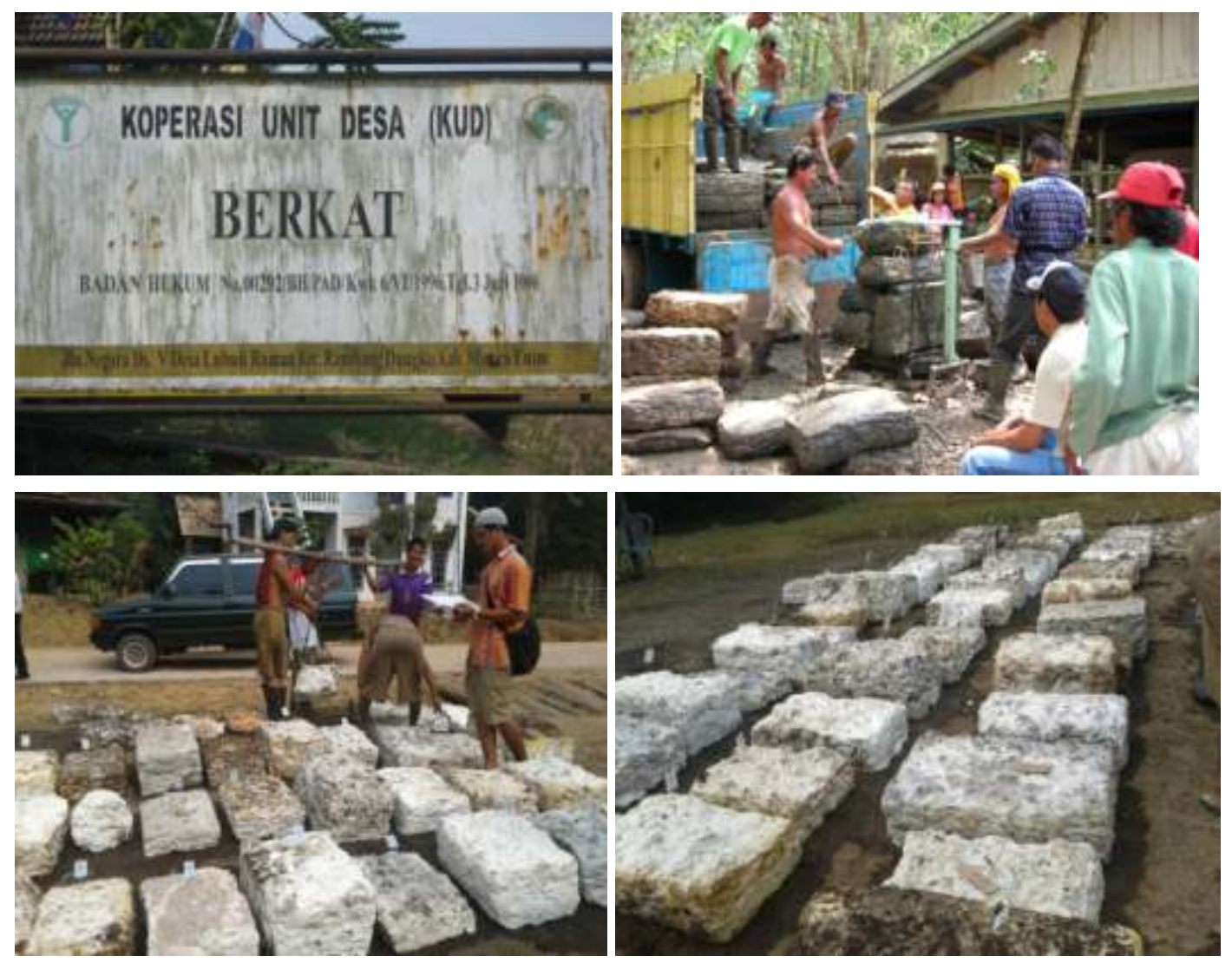

Gambar 3. Pemasaran bersama melalui lelang di KUD Kabupaten Muara Enim (atas) dan lelang di kelompok tani di Kabupaten Banyuasin (bawah)

Figure 3. Marketing through auctions at Village Cooperatives in Muara Enim (top) and farmer group in Banyuasin Regency (below)

\section{KESIMPULAN DAN SARAN}

Dari hasil kajian disimpulkan bahwa penerapan Peraturan Menteri Pertanian No. 38/Permentan/OT.140/8/2008 dan Peraturan Menteri Perdagangan No. 53/MDAG/PER/10/2009 mengenai upaya-upaya dalam meningkatkan mutu bokar belum dilaksanakan sepenuhnya di tingkat petani, dikarenakan sosialisasi mengenai peraturan-peraturan tersebut belum merata sepenuhnya dilaksanakan ke tingkat petani. Di samping itu, peraturan dari lembaga pemasaran juga masih belum tegas untuk menolak bokar mutu rendah yang dihasilkan petani. Permasalahan pengolahan dan pemasaran karet yang menyebabkan rendahnya mutu bokar dan pendapatan petani masih banyak terjadi di beberapa wilayah sampel di Sumatera Selatan. Hal ini terlihat dari tingkat kebersihan bokar, jenis pembeku, dan cara penyimpanan bokar yang sebagian besar belum memenuhi standar yang berlaku.

Beberapa saran dalam upaya memperbaiki mutu bokar di wilayah sampel adalah sebagai berikut:

1. Kondisi pengolahan dan mutu bokar di Kabupaten Muara Enim, Banyuasin, dan OKU Timur sudah cukup baik. Program peningkatan mutu bokar bagi desa-desa di wilayah-wilayah tersebut adalah dengan melakukan pengawalan dalam pemasaran agar petani bisa mendapatkan harga yang lebih baik dan termotivasi untuk terus meningkatkan mutu bokarnya antara lain dengan lebih banyak mengembangkan sistem pemasaran bersama oleh kelompok tani di desa-desa. 
2. Kondisi pengolahan dan mutu bokar di wilayah Kabupaten OKI, Musi Rawas, dan Lubuk Linggau masih memerlukan perhatian yang serius. Program perbaikan mutu bokar bagi desa-desa karet di wilayah tersebut adalah melalui program peningkatan pengetahuan dan motivasi petani untuk membuat bokar bersih dan menumbuhkan kelompokkelompok pemasaran bersama.

\section{DAFTAR PUSTAKA}

Anonim. 2012. Upaya Industri Karet Nasional Dalam Menghadapi Persaingan Pasar Karet Remah di Dunia Internasional. www.kdeitaipei.org., diakses pada tanggal 15 September 2012.

Balai Penelitian Sembawa. 2009. Saptabina Usahatani Karet Rakyat (edisi ke -5). Pusat Penelitian Karet. Balai Penelitian Sembawa, Palembang.

Direktorat Jenderal Perkebunan. 2011. Statistik Perkebunan Indonesia. Karet 2010-2012. Direktorat Jenderal Perkebunan, Jakarta.

Gabungan Perusahaan Karet Indonesia. 2010. Bulletin Karet. Gabungan Perusahaan Karet Indonesia, Jakarta.
Kementerian Perdagangan Republik Indonesia. 2009. Peraturan Menteri Perdagangan No. 53/2009. Pengawasan Mutu Bahan Olah Komoditi Ekspor Standard Indonesian Rubber yang Diperdagangkan. Kementerian Perdagangan Republik Indonesia, Jakarta.

Kementerian Pertanian Republik Indonesia. 2008. Peraturan Menteri Pertanian 38/2008. Pedoman Pengolahan dan Pemasaran Bahan Olah Karet (Bokar). Kementerian Pertanian Republik Indonesia, Jakarta.

Purbaya, M., T.I. Sari, C.A. Saputri, dan M.T. Fajriaty. 2011. Pengaruh Beberapa jenis bahan penggumpal lateks dan hubungannya dengan susut bobot, kadar karet kering dan plastisitas. Pros. Seminar Nas. AVoER (Added Value of Energy Resources) ke-3. Palembang, 26-27 Oktober. Fakultas Teknik Universitas Srwijaya, 351-357.

Wahyudi, F. 2008. Pengaruh Kombinasi Komposisi Bahan Olah Karet Terhadap Tingkat Konsistensi Plastisitas Indeks (PRI) Karet Remah SIR 20. Laporan Penelitian, Universitas Sumatera Utara, Medan. 
Lampiran 1. Wilayah sampel yang terpilih dalam penelitian Appendix 1. Sampling area in the study

\begin{tabular}{|c|c|c|}
\hline $\begin{array}{c}\text { Kabupaten } \\
\text { Districs }\end{array}$ & $\begin{array}{l}\text { Kecamatan } \\
\text { Sub Districs }\end{array}$ & $\begin{array}{c}\text { Jumlah Desa } \\
\text { Number of Village }\end{array}$ \\
\hline Musi Banyuasin & $\begin{array}{l}\text { Babat Supat } \\
\text { Bayung Lencir } \\
\text { Batanghari Leko } \\
\text { Lais } \\
\text { Tungkal Ilir } \\
\text { Sanga Desa }\end{array}$ & 11 \\
\hline Musi Rawas & $\begin{array}{l}\text { Muara Kelingi } \\
\text { Tuah Negeri } \\
\text { BTS Ulu } \\
\text { Muara Beliti } \\
\text { Tiang P. Kepungut } \\
\text { Karang Dapo } \\
\text { STL Ulu Terawas } \\
\text { Rawas Ulu }\end{array}$ & 12 \\
\hline Lubuk Linggau & LLG. Selatan & 2 \\
\hline Muara Enim & $\begin{array}{l}\text { Gunung Megang } \\
\text { Lubai } \\
\text { Rambang } \\
\text { Sungai Rotan } \\
\text { Gelumbang } \\
\text { Abab } \\
\text { Penukal } \\
\text { Talang Ubi } \\
\text { Tanah Abang }\end{array}$ & 15 \\
\hline Banyuasin & $\begin{array}{l}\text { Betung } \\
\text { Banyuasin III } \\
\text { Sembawa } \\
\text { Rambutan }\end{array}$ & 14 \\
\hline OKI & $\begin{array}{l}\text { Lempuing Jaya } \\
\text { Pangkalan lampam } \\
\text { Pampangan } \\
\text { Pedamaran Timur }\end{array}$ & 6 \\
\hline Ogan Ilir & Payaraman & 3 \\
\hline OKU Induk & $\begin{array}{l}\text { Semidang Aji } \\
\text { Lubuk Raja } \\
\text { Peninjauan } \\
\text { Lubuk Batang } \\
\text { Lengkiti } \\
\text { Sosoh Buay Rayap }\end{array}$ & 11 \\
\hline OKU Timur & $\begin{array}{l}\text { BP Peliung } \\
\text { BP Bangsa Raja } \\
\text { Belitang Madang Raya } \\
\text { Belitang III } \\
\text { Belitang Jaya } \\
\text { Semendawai Barat }\end{array}$ & 11 \\
\hline Kabupaten & 45 Kecamatan & 85 Desa \\
\hline
\end{tabular}

